\title{
Correction: Inherently chiral calix[4]arenes via oxazoline directed ortholithiation: synthesis and probe of chiral space
}

\author{
Simon A. Herbert, Laura J. van Laeren, Dominic C. Castell and Gareth E. Arnott ${ }^{*}$
}

\section{Correction}

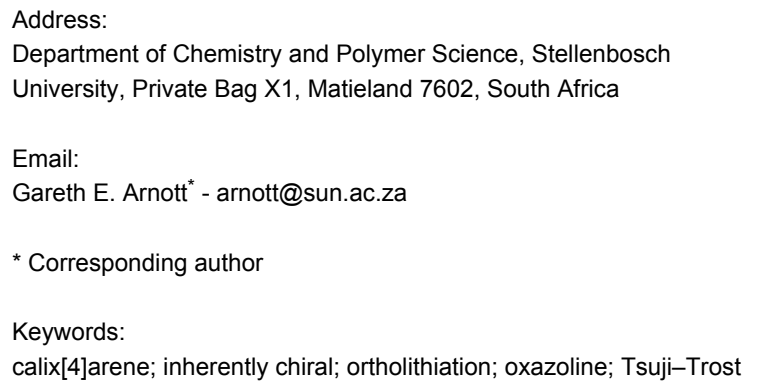

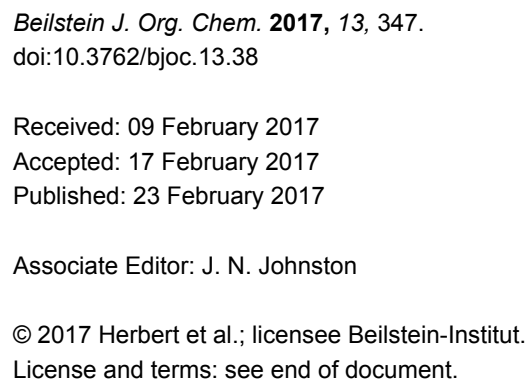

In Supporting Information File 1 of the original article a wrong flow rate and wrong retention times were reported on page s29. The correct flow rate is $1.1 \mathrm{~mL} / \mathrm{min}$ and the correct retention times are $\mathrm{Rt}_{1}: 6.01(\mathrm{R})$ and $\mathrm{Rt}_{2}: 6.64(\mathrm{~S})$. A corrected version of the Supporting Information File of the original article is given as Supporting Information File 1 of this Correction.

\section{Supporting Information}

Supporting Information File 1

Synthetic procedures and spectral data for all new compounds.

[http://www.beilstein-journals.org/bjoc/content/ supplementary/1860-5397-13-38-S1.pdf]

\section{License and Terms}

This is an Open Access article under the terms of the Creative Commons Attribution License (http://creativecommons.org/licenses/by/4.0), which permits unrestricted use, distribution, and reproduction in any medium, provided the original work is properly cited.

The license is subject to the Beilstein Journal of Organic Chemistry terms and conditions:

(http://www.beilstein-journals.org/bjoc)

The definitive version of this article is the electronic one which can be found at: $\underline{\text { doi: } 10.3762 / \text { bjoc. } 13.38}$ 